\title{
Clonal Chromosome Abnormalities in 54 Cases of Ovarian Carcinoma
}

\author{
F. H. Thompson, J. Emerson, D. Alberts, Y. Liu, X-Y. Guan, \\ A. Burgess, S. Fox, R. Taetle, R. Weinstein, R. Makar, \\ D. Powell, and J. Trent
}

\begin{abstract}
As a prelude to assessing the relationship of chromosome alterations to clinical outcome in ovarian carcinoma, we report on the cytogenetic analysis on short-term cultures from 54 patients. All patients had histopathologically confirmed malignancy, with the majority of cases demonstrating serous ovarian adenocarcinomas. Structural alterations were evident in 52 cases, whereas numeric changes were identified in 13 cases. The most notable numeric abnormalities were loss of the X-chromosome (9/13 total cases) and +7 (3/9 diploid cases). Structural alterations most frequently involved chromosomes 1, 3, 6, 7, 11, and 12. Chromosomal breakpoints were shown to cluster in several chromosomal banding regions, including 1p36, 1p11-q21, 3p23-p10, 7p (especially 7p22), 11p, 11q, 12p13-q12, and 12q24. The frequency of structural alterations involving the following chromosome arms was found to be significantly increased: $1 p(p<0.01), 7 p(p<0.01), 11 p(p<0.01), 11 q(p<0.05)$, and 12p $(p<0.05)$. An analysis of the net gain or loss of chromosome segments was also performed, with the most consistent tendency observed being over-representation of 1q and chromosome 7 , deletion of $1 p$, and loss of the X chromosome.
\end{abstract}

\section{INTRODUCTION}

Ovarian cancer continues as the leading cause of death from gynecologic cancer in the United States, with an estimated 20,700 new cases and 12,500 deaths in 1991 [1]. This cancer is most common in Western countries, with the incidence per 100,000 population being highest in Sweden (21.0) but nearly as high in white females in the United States (15.6) [2]. In contrast, the incidence is as low as 3.1 per 100,000 in Japan [2].

Previously described prognostic factors from prospective, randomized studies of patients with stages III and IV disease include: patient age < 50 years; performance status 0-1 (SWOG); stage III disease; absence of macroscopic tumor at the end of initial exploratory laparotomy; and well-differentiated (i.e., grade 1) serous cystadenocarcinoma histopathology [3-8]. Commonly, the most important predictor of survival in patients with stage III cancers is the degree of residual disease remaining following initial exploratory

From the Arizona Cancer Center (F. H. T., J. E., Y. L., S. F, R. T.), Section of Hematology and Oncology, Department of Medicine (D. A.), and Department of Pathology (R. W., R. M.), University of Arizona, Tucson, Arizona; Department of Pathology and Laboratory Medicine (D. P.), University of Kentucky, College of Medicine, Lexington, Kentucky; and the University of Michigan Medical Center (X-Y. G., A. B.), Departments of Radiation Oncology and Human Genetics (J. T.), Ann Arbor, Michigan.

Address requests to: Floyd $H$. Thompson, Cytogenetic Oncology Lab, Arizona Cancer Center, 1515 N. Campbell Ave. Tucson, AZ, 85724.

Received June 21, 1993; accepted August 31, 1993. laparotomy [3-5]. Additionally, the serum CA-125 concentration after chemotherapy may prove an independent prognostic factor with respect to survival duration in patients with advanced ovarian cancer [9-13]. However, there is also an ongoing search for a pretreatment predictor of prognosis. A potentially important area is the identification of specific cytogenetic abnormalities in the ovarian tumors.

Relatively little is known of specific cytogenetic alterations in ovarian cancer, particularly for tumor karyotypes from the primary specimens and regional metastatic sites at initial laparotomy. Metastatic specimens (including ascites fluids) show frequent rearrangements (or allelic loss of heterozygosity) involving 3p, 6q, 11p, 17q, and 17p13 [14-16]. However, the only karyotypic alteration that has been shown to be associated with ovarian cancer as a primary change is +12 , also found in benign tumors (fibromas, thecomas, and adenomas of the ovary) [15]. Clearly, given the importance of this tumor, further knowledge regarding the cytogenetics of this disorder would be useful. In this report, we describe cytogenetic findings in 54 cases of previously unpublished ovarian carcinoma.

\section{MATERIALS AND METHODS}

\section{Pationt Population}

Solid tumor samples for cytogenetic analysis were obtained from patient with clinical ovarian cancer at initial laparotomy. During the period from January 1987 to April 1991, 480 ovarian tumor samples were received; 317 of these samples 
(66\%) were successfully cultured. From this group 169 samples (from 165 patients) met eligibility criteria for study inclusion, specifically: origin from a solid tumor sample from a newly diagnosed patient previously untreated for epithelial ovarian cancer. Of these 165 patients, clonal abnormalities were detected in 84 patients ( $\sim 50 \%$ ). The present series describes the first 54 patients with clonal abnormalities on whom systematic histopathologic review has been completed.

Histopathologic review of tumor tissue confirmed the diagnosis of primary ovarian epithelial malignancy. Histologic classification based on standard WHO criteria [17] was performed independent of karyotype data. Tumors were graded histologically as well, moderately, or poorly differentiated according to a grading system utilizing a combination of architectural, cytoplasmic, and nuclear features as described by Russell and Bannatyne [18]. Clinical staging was based on FIGO classification criteria [19].

\section{Cytogenetic Analysis}

Cytogenetic analysis was performed as previously described [20] after short-term culture (1-32 days, mean $=8.2$ days) in either McCoy's, RPMI-1640, or modifications of L15 medium [21]. Typically, 25 or more metaphases were counted and examined, and a minimum of five karyotypes (and generally 10 or more) of the modal population were prepared. Description of karyotypic abnormalities followed the recommendations of the ISCN $[22,23]$. Structural abnormalities were identified as clonal if found in two or more cells. Numeric changes (two or more cells for gain, three or more cells for loss) were described relative to ploidy of the abnormal modal population, as per the recommendations of the Cancer Cytogenetics Supplement [1991], and these were determined only if a mode or modal range represented at least $20 \%$ of the cells counted.

\section{Statistical Analysis of Chromosomal Alterations}

The frequency of occurrence of structural abnormalities was analyzed using the statistical approach of Brodeur et al. [24]. This method allows assessment of statistically significent involvement of particular chromosome arms. With this method, the expected probability of structural abnormalities is assumed to be proportional to chromosome arm length and chromosomal abnormalities are assumed to occur as independent events.

\section{Segment Representation Profiles}

An analysis to assess the recurrent gains or losses of specific chromosomal segments was performed. We have termed this approach a chromosomal segment representation profile (CSRP) [25]. This analysis takes into account both gain and loss of normal chromosomes and the presence of structurally altered homologs, with the combined results producing a visual representation of the net gain or loss of chromosomes or chromosomal segments. CSRP analysis was performed only in cases in which the abnormal cell populations had defined modes ( $\geqslant 20 \%$ of cells examined) and karyotypes. Additionally, CSRPs were all described relative to diploid, as we wished to study the effects of karyotype alterations acquired by the normal progenitors.
Table 1 Clinicopathologic characteristics of ovarian cancer cases

\begin{tabular}{|c|c|c|c|c|}
\hline Case & Age & Histologic type & $\begin{array}{l}\text { Clinical } \\
\text { Stage }\end{array}$ & $\begin{array}{l}\text { Histologic } \\
\text { Differentiation }\end{array}$ \\
\hline T87-112 & 58 & Serous & III & Poor \\
\hline T87-134 & 64 & Serous & IV & Poor \\
\hline Т88-173 & 57 & Serous & IV & Moderate \\
\hline T88-178 & 62 & Undifferentiated & I & Poor \\
\hline T88-183 & 71 & Serous & III & Poor \\
\hline T88-207 & 50 & Serous & III & Poor \\
\hline T88-267 & 65 & Endometroid & III & Poor \\
\hline T88-286 & 76 & Undifferentiated & III & Poor \\
\hline T88-297 & 38 & Serous & III & Poor \\
\hline T88-301 & 51 & Serous & III & Poor \\
\hline T88-304 & 65 & Serous & III & Moderate \\
\hline T88-320 & 40 & Serous & IV & Poor \\
\hline T88-339 & 65 & Serous & III & Moderate \\
\hline T88-372 & 69 & Serous & III & Poor \\
\hline T88-411 & 66 & Serous & III & Well \\
\hline T89-003 & 34 & Undifferentiated & III & Poor \\
\hline T89-007 & 81 & Endometroid & III & Poor \\
\hline T89-026 & 43 & Undifferentiated & III & Poor \\
\hline T89-032 & 40 & Serous & III & Poor \\
\hline T89-052 & 45 & Serous & III & Poor \\
\hline T89-060 & 54 & Serous & III & Moderate \\
\hline T89-070 & 46 & Undifferentiated & III & Poor \\
\hline T89-097 & 63 & Serous & III & Moderate \\
\hline T89-107 & 61 & Clear cell & III & Moderate \\
\hline T89-126 & 44 & Endometroid & IV & Moderate \\
\hline T89-133 & 69 & Serous & III & Poor \\
\hline T89-134 & 59 & Serous & III & Poor \\
\hline T89-143 & 72 & Serous & III & Moderate \\
\hline T89-148 & 57 & Endometroid & III & Moderate \\
\hline T89-154 & 61 & Serous & III & Well \\
\hline Т89-232 & 30 & Serous & III & Well \\
\hline T89-243 & 61 & Undifferentiated & III & Poor \\
\hline T89-244 & 85 & Serous & II & Moderate \\
\hline T89-321 & 38 & Endometroid & I & Well \\
\hline T89-348 & 62 & Serous & III & Poor \\
\hline T90-023 & 71 & Serous & III & Poor \\
\hline T90-031 & 62 & Mucínous & III & Poor \\
\hline T90-062 & 71 & Serous & III & Moderate \\
\hline T90-063 & 65 & Serous & IV & Poor \\
\hline T90-064 & 52 & Serous & III & Poor \\
\hline T90-067 & 48 & Serous & III & Moderate \\
\hline T90-068 & 58 & Serous & IV & Poor \\
\hline T90-073 & 53 & Serous & III & Moderate \\
\hline T90-116 & 69 & Endometroid & III & Moderate \\
\hline T90-123 & 73 & Serous & III & Poor \\
\hline T90-146 & 64 & Serous & III & Well \\
\hline T90-216 & 55 & Serous & II & Poor \\
\hline T90-245 & 69 & Endometroid & IV & Moderate \\
\hline T90-248 & 58 & Serous & III & Moderate \\
\hline T90-257 & 38 & Serous & III & Moderate \\
\hline T91-007 & 60 & Endometroid & IV & Moderate \\
\hline T91-010 & 70 & Serous & III & Poor \\
\hline T91-015 & 61 & Serous & III & Poor \\
\hline T91-094 & 66 & Serous & III & Moderate \\
\hline
\end{tabular}

\section{RESULTS}

Clinicopathologic characteristics of the 54 patients are summarized in Table 1. A majority $(70 \%)$ had serous ovarian 
adenocarcinomas. Most (93\%) had Stage III or IV disease, and more than half ( $56 \%$ ) had Grade III tumors. The average age of patients at the time of diagnosis was 59 years, with the range being 30-85 years. Tumors from 52 of the 54 patients in this series $(96 \%)$ had clonal structural abnormalities, while 13 of 54 patient tumors $(24 \%)$ had defined abnormal model populations and clonal numeric abnormalities.

A majority of cases had modes that were near diploid, with one case being pseudo-diploid (T88-411). In six cases, the mode was normal diploid, but the abnormal cell component (sideline) did not have a modal number as defined by $\geqslant 20 \%$ of cells examined. Seven cases were bimodal in chromosome numbers, with one mode of 46 in each case.
Eleven cases were so heterogeneous or complex that no modal numbers could be determined.

Normal metaphases were found in 12 cases, presumably representing mixtures of tumor and nontumor cells. In 22 cases extremely complex abnormal chromosome preparations were obtained. These cells typically contained fragmented chromosomes, quadriradials and/or triradials, and varying complex structural rearrangements such that complete karyotype descriptions were not possible. This finding is characteristic of ovarian carcinomas but rare in other tumors [26]. An example of such a cell is shown in Figure 1. The small proportion of cases with clonal numeric abnormalities is no doubt due in part to the presence of these com-

Figure 1 (A) Example of a highly abnormal, unanalyzable chromosome spread from case T90-067. The presence of this kind of cell helped define the AX karyotype profile assigned to this and similar cases. (B) Examples of clonal structural abnormalities identified in case T90-248 (another case with an AX profile). See Table 1 for AX definition.

A
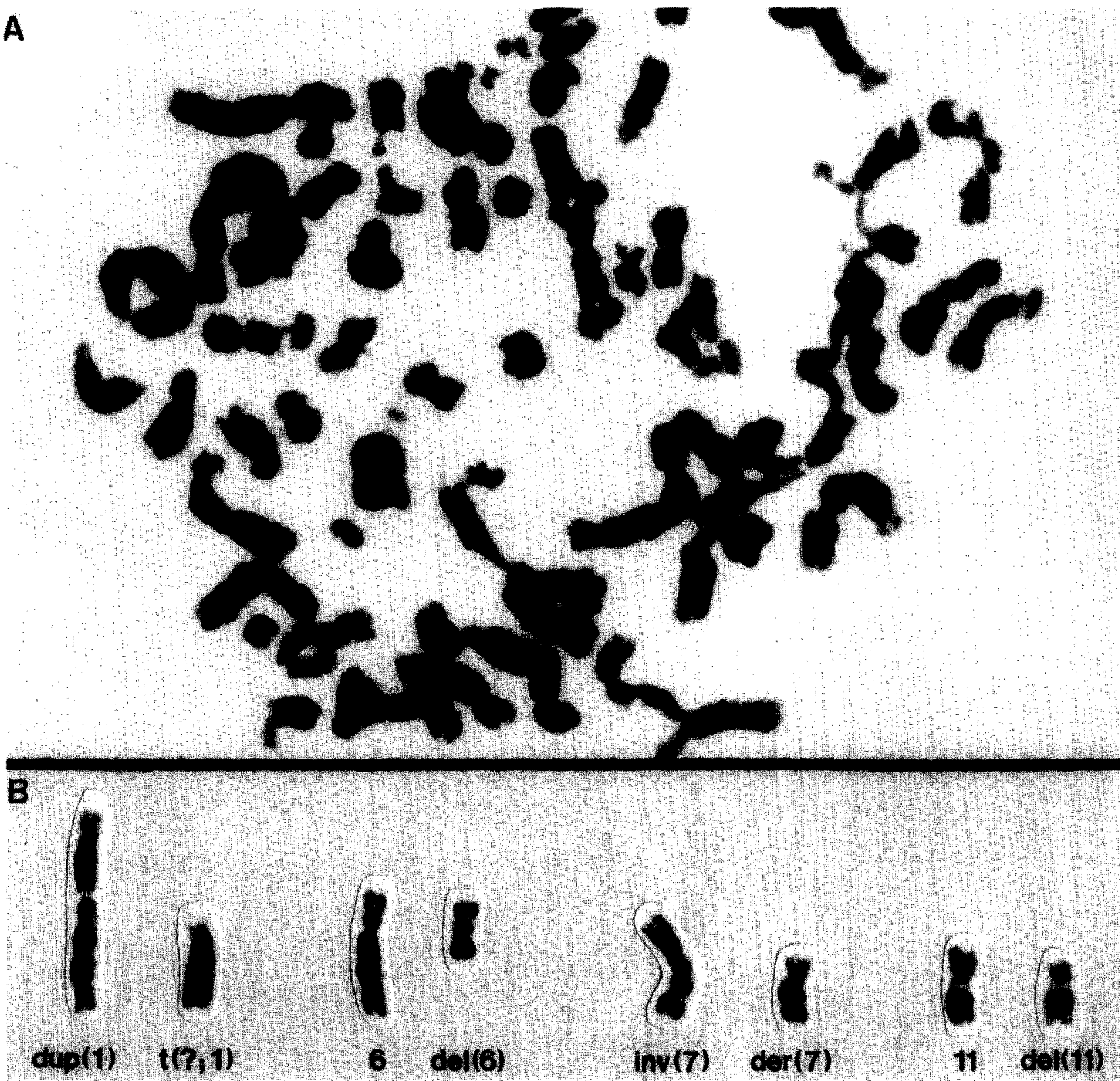
Table 2 Karyotypes from 54 cases of ovarien carcinoma

\begin{tabular}{|c|c|c|c|}
\hline Case ID & Sample ${ }^{a}$ & Profile ${ }^{b}$ & Karyotype \\
\hline T87-112 & Omentum & AN & $46, X X / 56-57, X X, \operatorname{del}(1)(q 10), \operatorname{del}(1)(p 10), \operatorname{add}(11)(p 15), \operatorname{add}(12)(p 11)$, inc \\
\hline T87-134 & Primary & NX & 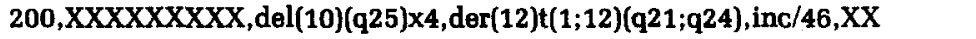 \\
\hline T88-173 & Primary & AA & $55-170, X X, \operatorname{del}(1)(q 21), \mathrm{add}(6)(q 25), \operatorname{der}(12) \mathrm{t}(12 ; 14)(\mathrm{p} 13 ; \mathrm{q} 13)$, inc \\
\hline T88-178 & Primary & $\mathrm{AX}$ & $\begin{array}{l}\text { 37-120,XX,add(6)(q13), del(11)(p13), hsr(11)(q22), der(11)add(11)(p14) } \\
\text { add(11)(q23),add(12)(p12),inc }\end{array}$ \\
\hline T88-183 & Omentum & AA & $\begin{array}{l}\text { 56-63,XX, +X,dup(12)(q24q21),der(12)dup(12)(q24q11)dup(12) } \\
\text { (q11q21),inc }\end{array}$ \\
\hline T88-207 & Primary & $\mathrm{AX}$ & $43-44, X X, \operatorname{del}(1)(q 25), a d d(5)(p 15)$, inc \\
\hline T88-267 & Omentum & AN & $46, X X / 39-105, X X, d e l(1)(p 21), d \theta l(1)(q 25)$, inc \\
\hline T88-286 & Primary & AA & $\begin{array}{l}\text { 45, }-X,-X, \text { add(1)(p36.5),i(1)(q10), add(5)(p15),t(6;13)(q25;q34), }-15,-16 \text {, } \\
\quad t(18 ; 22)(p 11.1 ; q 11.2),-19,+3 \operatorname{mar}[\mathrm{cp}]\end{array}$ \\
\hline T88-297 & Mets $^{c}$ & AA & $\begin{array}{l}\text { 32-75,X,del(X)(q23), add(1)(p11), del(7)(q32), der(13)t(11;13)(q12;q22), } \\
\text { add(16)(q13),add(17)(q25),inc }\end{array}$ \\
\hline T88-301 & Omentum & AX & $41-45, X X, \operatorname{add}(1)(q 44), \operatorname{add}(7)(q 36)$, inc \\
\hline T88-304 & Omentum & AA & 41-147,XX, del1(2)(p15),hsr(7)(p21),add(11)(p15),inc \\
\hline T88-320 & Omentum & AA & $\begin{array}{l}\text { 35-67,XX, del(1)(p34), add(3)(p25), add(6)(q27), hsr(6)(p22), add(7)(q36), } \\
\text { del(7)(p15), del(7)(q31), add(11)(q25),ider(12)(q10)del(12)(q22), inc }\end{array}$ \\
\hline T88-339 & Primary & AA & $\begin{array}{l}\text { 53-58,XX, add(2)(q34), add(3)(p11), add(12)(p11), add(16)(q24), add(19) } \\
(q 13.5), \text { inc }\end{array}$ \\
\hline T88-372 & Omentum & AA & $\begin{array}{l}80-88, X X,-X,-X, \text { add }(1)(p 11), \text { add(1)(p33), del(1)(q23), }-2,-2,-3,-3, \\
\text { add(3)(q27),-4,-4,-5,-5,-6,-6,del(7)(p14), +del(7)(q34), -8,-8, } \\
-9,-9,-10,-11,-13,-14,-15,-15,-16,-17,-18,-18,-19,-19 \\
-20,-21,-22,-22,-2,+15 \operatorname{mar}[c p]\end{array}$ \\
\hline T88-411 & Primary & AA & $46, \mathrm{XX} / 44-92, \mathrm{XX}, \mathrm{hsr}(17)(\mathrm{q} 25)$, inc \\
\hline T89-003 & Abdominal wall & $\mathrm{AX}$ & $56-143, X X$, add(1)(p31), add(11)(q24), inc \\
\hline T89-007 & Primary & $\mathrm{AX}$ & 46-100,XXXX,del(3)(p13),inc \\
\hline T89-026 & Primary & $\mathrm{AX}$ & $41, X X, \operatorname{del}(6)(q 16), \operatorname{der}(7)$ add $(7)(p 22)$ add(7) $(q 34)$, inc \\
\hline T89-032 & Primary & AX & $38, X X$, add $(12)(q 24)$, inc \\
\hline T89-052 & Omentum & $\mathrm{AX}$ & $\begin{array}{l}67-72, X X X, \text { add }(1)(p 34), \text { add }(1)(q 32), \operatorname{del}(3)(q 13), \text { add }(6)(p 22) \times 2 \text {, } \\
\text { add }(11)(q 23), \text { inc }\end{array}$ \\
\hline T89-060 & Primary & AA & $45, X,-X,-1, \operatorname{der}(9) t(1 ; 9)(q 11 ; p 13) \times 2,+\operatorname{mar}[c p]$ \\
\hline T89-070 & Omentum & AN & $\begin{array}{l}\text { 46,XX/44,XX, add }(1)(p 36), \text { add }(6)(q 22), \text { add }(7)(p 22), \operatorname{der}(11) t(11 ; 11)(p 15 ; q 13) \\
\text { dup(11)(q13q25), + 12mar,inc }\end{array}$ \\
\hline T89-097 & Mets $^{c}$ & AA & $\begin{array}{l}64, X X,-X, \operatorname{del}(1)(p 35) \times 2,+\operatorname{hsr}(1)(p 33), \operatorname{add}(2)(q 37),-4, \operatorname{der}(6) t(5 ; 6) \\
(q 11 ; q 24),+\operatorname{add}(7)(q 11), \operatorname{der}(7) t(7 ; 11)(q 11 ; q 13) \times 2,-8,-11, \operatorname{del}(11)(q 21) \\
\operatorname{del}(12)(p 12),-13,-14,-14, \operatorname{add}(15)(p 11),-17,-18,-18,-19,-20 \\
{[c p]}\end{array}$ \\
\hline T89-107 & Omentum & NX & $46, X X / 36-37, X X, \operatorname{add}(11)(p 14), \operatorname{del}(12)(\mathrm{p} 12.1)$, inc \\
\hline T89-126 & Primary & AA & 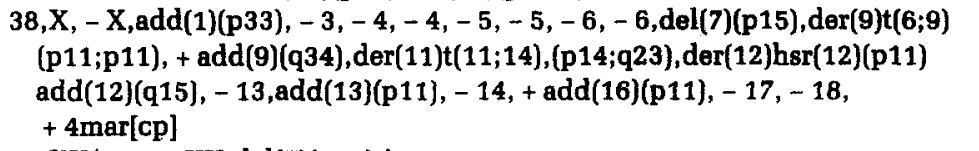 \\
\hline T89-133 & Omentum & AN & $46, X X / 50-54, X X, \operatorname{del}(7)(p 12)$,inc \\
\hline T89-134 & Intraperitoneal & AA & $\begin{array}{l}\text { 43,XX, add(1)(p36), add(3)(q29), add(3)(q29), hsr(6)(p21),add(7)(q31), add(11) } \\
\text { (q13), del(12)(p12), der(14)t(13;14)(q11;p13), + 7mar,inc }\end{array}$ \\
\hline T89-143 & Mets $^{c}$ & AN & $46, X X / 45-66, X X$, add $(5)(q 35)$, add $(9)(p 24)$, inc \\
\hline T89-148 & Primary & AA & $39, X, \operatorname{add}(X)(q 28), i(1)(q 10), \operatorname{der}(1) t(1 ; 11)(p 36 ; q 13)$, inc \\
\hline T89-154 & Jejunum & AA & $46, X,-X,+i(1)(q 10),+7,-22 / 45, X,-X, i(1)(q 10),+7,-22$ \\
\hline T89-232 & Primary & AA & $47, X X,+8 / 48, X X,+7,+8$ \\
\hline T89-243 & Primary & AX & $69-72, X X X$, add $(1)(p 32), \operatorname{del}(6)(q 23), \operatorname{del}(7)(p 12)$, add(11)(p15),inc \\
\hline T89-244 & Primary & $\mathrm{AX}$ & 49-76,XXX, add(3)(p26), add(12)(q24),inc \\
\hline T89-321 & Adnexa & AA & $49, X X,+\operatorname{del}(3)(q 21),+7,+7$ \\
\hline T89-348 & Adnexa & $\mathrm{AX}$ & $56-57, X X$, del(1)(p12), add(1)(p11), del(6)(q15), hsr(11)(p14), add(12)(q24), inc \\
\hline T90-023 & Primary & AA & $\begin{array}{l}43, X,-X,-1, \operatorname{del}(1)(q 24 q 32),+12,-13,-14,-15, \operatorname{der}(16) t(1 ; 16)(q 21 ; q 24) \\
-18,-19, \operatorname{add}(22)(q 13),+3 \operatorname{mar}[c p]\end{array}$ \\
\hline T90-031 & Primary & AA & $\begin{array}{l}68-70, \mathrm{XXX},+\mathrm{X},+1,+3,-4, \operatorname{der}(7) \mathrm{t}(7 ; 9)(\mathrm{p} 22 ; \mathrm{q} 12) \times 2,+8,-12,-13,-14 \\
-16,-17,-19,+20,+4 \operatorname{mar}[\mathrm{cp}]\end{array}$ \\
\hline T90-062 & Primary & AX & $\begin{array}{l}\text { 65,XXX,i(1)(q10), der(7)t(3;7)(q13;p21),her(11)(p11), der(17)t(8;17) } \\
\text { (q11;p13),i(21)(q10),inc }\end{array}$ \\
\hline T90-063 & Primary & NX & $46, \mathrm{XX} / 68-72, \mathrm{XXX}$, add(1)(p36.5), add(12)(p13),inc \\
\hline T90-064 & Primary & AN & $46, X X c / 45, X,-X c$ \\
\hline
\end{tabular}


Table 2 Continued

\begin{tabular}{|c|c|c|c|}
\hline Case ID & Sample ${ }^{a}$ & Profile $^{b}$ & Karyotype \\
\hline T90-067 & Primary & $\mathrm{AX}$ & 40-170,XX, add(1)(p36.5),inc \\
\hline T90-068 & Primary & $\mathbf{A X}$ & $39-40, X X, \operatorname{add}(7)(p 22), \operatorname{del}(11)(p 11), t(11 ; 11)(p 11 ; q 24)$, inc \\
\hline T90-073 & Primary & AN & $46, X X / 46-87, X X X, i(6)(p 10)$, add $(10)(q 26) \times 2$, add $(11)(q 23) \times 2$, inc \\
\hline T90-116 & Primary & $\mathrm{AX}$ & 36-75,XX,add(11)(p15),inc \\
\hline T90-123 & Omentum & AA & 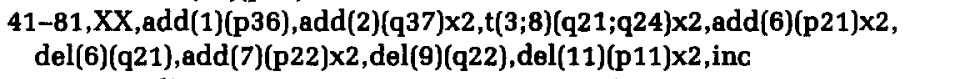 \\
\hline T90-146 & Primary & AA & $43-44, X X, \operatorname{idic}(1)(\mathrm{p} 12),-13,-15,-18,-22[\mathrm{cp}]$ \\
\hline T90-216 & Primary & AN & $\begin{array}{l}46, X X / 27-84, X X, \operatorname{der}(3) t(3 ; 6)(q 29 ; p 12), a d d(7)(p 11), \operatorname{der}(7) t(7 ; 15)(p 22 ; q 11) \\
\quad \operatorname{dup}(12)(q 21 q 24), \operatorname{add}(17)(q 24), \operatorname{add}(19)(q 13), \operatorname{der}(22) t(13 ; 22)(q 11 ; p 11) \times 2 \\
\quad+6 \text { mar,inc }\end{array}$ \\
\hline T90-245 & Omentum & $\mathrm{AX}$ & 60-61,XXX,der(6)add(6)(p24)del(6)(q23),add(11)(p15),add(11)(p15),inc \\
\hline T90-248 & Primary & $\mathrm{AX}$ & 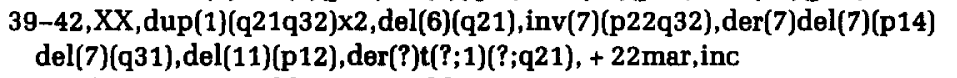 \\
\hline T90-257 & Omentum & NX & $46, X X / 61-70, X X X$, add(2)(q37), add(11)(q23),inc \\
\hline T91-007 & Primary & AA & $\begin{array}{l}\text { 67-71,XXX,hsr(2)(q21), del(3)(p21), der(3)t(1;3)(q21;p13), der(7)t(1;7) } \\
\text { (p12;p11),del(10)(q23),del(11)(q14),der(11)add(11)(p15)add(11)(q23), } \\
\text { add(11)(q14),add(16)(p13),inc }\end{array}$ \\
\hline T91-010 & Primary & AA & $\begin{array}{l}\text { 45-50,XX, del(1)(p22)x2, add(5)(p13),t(3;7)(p14;p21),i(6)(p10), add(7)(p22), } \\
\operatorname{der}(7) t(7 ; 8)(q 36 ; q 12), \text { add }(11)(q 25),+14 \text { mar,inc }\end{array}$ \\
\hline T91-015 & Omentum & AA & 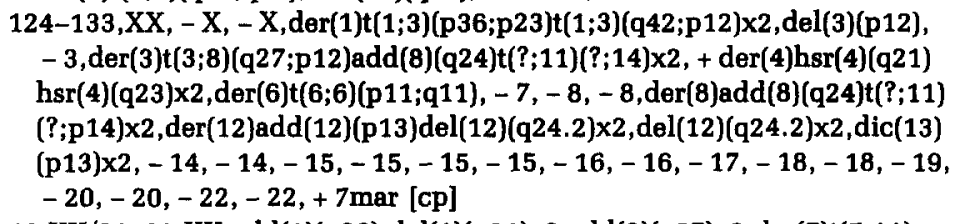 \\
\hline T91-094 & Mets $^{c}$ & NX & 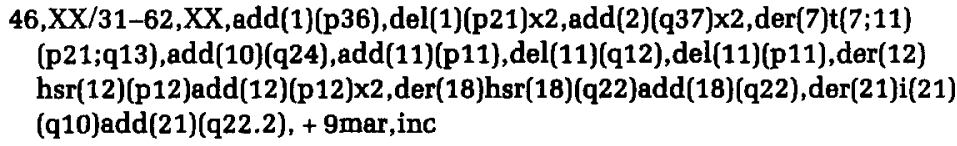 \\
\hline
\end{tabular}

a Primary ovarian tumor or site of regional metastases.

${ }^{b} \mathrm{AA}=$ all abnormal metaphases; $\mathrm{AX}$ = all abnormal metaphases, but some too complexly abnormal and/or fragmented and/or with quadriradials so that they cannot be fully analyzed; $\mathrm{AN}=$ a mixture of normal and abnormal cells; $\mathrm{NX}=\mathrm{a}$ mixture of normal and complexly abnormal cells.

c Unspecified regional metastatic sample from the lower abdominal cavity.

plexly abnormal cells that could not be fully characterized. Although cases with AX and NX profiles contained highly abnormal and only partially analyzable metaphases (as shown in Figure 1A), it was possible to identify clonal structural abnormalities in these cases. The clonal rearrangements identified from a case with an AX profile, T90-248, are presented in Figure 1B.

Cases were assigned to karyotype profiles (defined in footnote, Table 2) to indicate whether or not they contained mixtures of normal, abnormal, or complexly abnormal cells (Table 2). The overall distribution of karyotype profiles was: 17 cases AX (32\%), 24 cases AA ( $44 \%$ ), eight cases AN (15\%), and five cases NX (9\%). An overview of the relationships between karyotype profile and ploidy of mainlines is shown in Figure 2. Not surprisingly, among cases with near-diploid modes there was a higher proportion of cases with $\mathrm{NX}$ and AN karyotype profiles, whereas cases that had no defined mode had exclusively $\mathrm{AX}$ or AA profiles.

Examples of representative G-banded karyograms from three cases are shown in Figures 3-5. These karyotypes demonstrate abnormalities found in pseudodiploid, hyperdiploid, and polyploid cells.

There was a tendency to loss of chromosomes relative to ploidy level, particularly for the near-triploid cases. The most common numeric abnormality was loss of at least one $\mathrm{X}$ chromosome, observed in 9/13 cases (six near-diploid, and three near-triploid abnormal modes). The only chromosomes present in excess copy number (one or more additional homologs) in near-diploid cases were chromosomes 7 (3/9 cases), 8 , and 12 (one case each). The significance of numeric abnormalities relative to triploid is not clear.

Two cases showed only numeric alterations. The stemline and mainline karyotype of T89-232 was $47, \mathrm{XX},+8$ (in $60 \%$ of the metaphases examined), whereas the sideline in this case was $48, X X,+7,+8(40 \%)$. In case T90-064, the mainline was $46, \mathrm{XX}$ and appeared normal, whereas the sideline was $45, X$ ( $43 \%$ of cells). Because of the possibility that clonal loss of X represented a constitutional chromosomal abnormality, peripheral blood was obtained and analyzed, confirming the suspicion that this patient was a previously undiagnosed Turner's syndrome mosaic. This patient's case will be reported in more detail separately.

A detailed description of clonal structural abnormalities and their profiles (i.e., karyotype mixtures) is given in Table 2. Among the 52 patients with structural abnormalities, chromosomes $1,6,7,11$, and 12 showed the highest frequency 

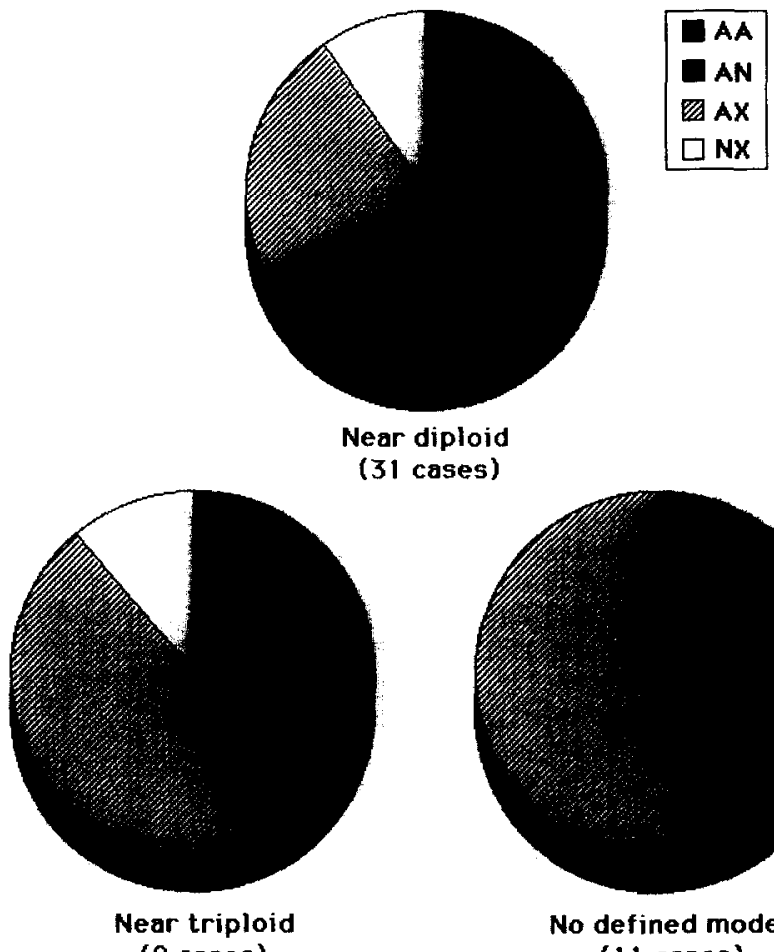

( 9 cases)

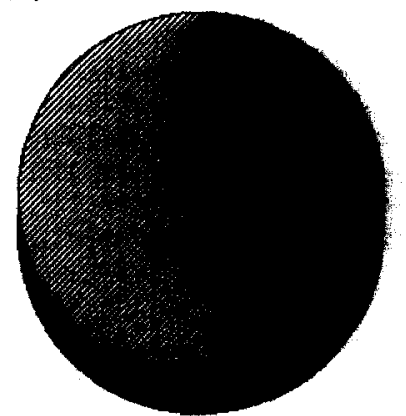

No defined modes (11 cases)

Figure 2 Pie charts demonstrating the relationship between karyotype profiles and ploidy levels of the modal populations in this series of ovarian carcinoma tumors. Bimodal cases were assigned to the ploidy level of the mainline.

of involvement. Abnormalities of chromosome 1 were detected in $32 / 52$ patients ( $62 \%$ ), whereas $19 / 52$ (37\%) had abnormalities of chromosome $6,21 / 52(40 \%)$ had abnormalities of chromosome $7,27 / 52(52 \%)$ had abnormalities of chromosome 11 , and $18 / 52$ (35\%) had abnormalities of chromosome 12. The distribution of chromosomal abnormalities according to arm involved in shown in Figure 6. Using the method of Brodeur et al. [24], the frequency of involvement of the following chromosome arms was found to be significantly increased: $1 p(p<0.01), 7 p(p<0.01), 11 p(p<0.01)$, $11 q(p<0.05)$, and $12 p(p<0.05)$. A number of structural abnormalities involved chromosome 3 , but the frequency of these anomalies was not statistically significant. A summary of all breakpoints identified collectively from clonal abnormalities in this set of patient samples is shown in Figure 7. The chromosomal regions most often affected by structural abnormalities were 1p36, 1p11-q21, 3p23-p10, 7p (especially 7p22), all of chromosome 11, 12p13-q12, and 12q24.

Few recurring structural abnormalities were identified, except for translocations of frequently unknown material to 1p36. Examples of these translocations are shown in Figure 8. In Figure 8 , the translocated material in the $1 p+$ marker from case T89-148 was thought to be derived from a chromosome 11, while the origin of translocated material in 1p + markers from all other cases remains unidentified.

Isochromosomes were found in seven cases and included $i(1 q)$ in two cases, and $i(6 p)$ in two cases. Cytologic evidence of possible gene amplification in the form of homogeneously

staining regions (HSRs) was found in 12 cases (two ceses each on $6 p, 11 p$, and $12 p$, and one case each on $1 p, 2 q, 4 q, 7 p, 17$, and 18q). Apparently simple, terminal deletions of chromosomes were found in $46 / 54$ cases ( $85 \%$ ), including deletions of $1 p$ (seven cases), $1 q$ (six cases), $6 q$ (five cases), and $7 q$ and 11p (four cases each). Generally more common were unbalanced and nonreciprocal translocations sometimes involving material of uncertain origin.

In this series of patients, it was possible to perform CSRP analysis on 13 patients. These results, summarized in Figure 7, document a tendency to gain chromosomes or chromosomal segments, relative to diploid. Net gain most notably involved the long arm of chromosome 1 and all of chromosome 7 (often with material of unknown origin translocated to the 7pter), while net loss involved the X chromosome and deletion of $1 \mathrm{p}$.

An interesting relationship between chromosome 6 abnormalities and histology was noted in our patient series. Specifically, $83 \%$ (5/6 cases) of tumors with an undifferentiated histology displayed structural rearrangements of chromosome 6 , whereas only $32 \%$ (12/38 cases) of serous tumors and $25 \%$ ( $2 / 8$ cases) of endometrioid tumors had abnormalities of chromosome 6 ( $p=0.04, \chi^{2}$ test). In contrast, structural alterations of chromosome 1 (which were the most frequent) did not seem to be related to histology in our series, where $67 \%$ of undifferentiated ( $4 / 6$ cases), $63 \%$ of serous ( $24 / 38$ cases), and $50 \%$ of endometrioid ( $4 / 8$ cases) tumors displayed such rearrangements.

\section{DISCUSSION}

Prior to initiating therapy for solid or hematologic malignancies, it is useful to estimate the patient's relative prognosis to fully inform them of the risk/benefit ratio as well as to select the most appropriate and potentially effective treatment. There are well-documented prognostic factors associated with advanced ovarian cancer, including patient age, performance status, stage, degree of residual intrapelvic and intra-abdominal tumor after resection, and histologic grade of tumor. Although each characteristic has been associated with survival in retrospective analyses [3-8], there is a continued search for tumor-specific factors that prospectively and independently predict ovarian cancer patient survival. We evaluated clonal karyotype abnormalities in 54 patients newly diagnosed with advanced ovarian cancers in an attempt to identify specific cytogenetic changes which may be associated with the prognosis of this disease.

Our cytogenetic findings both confirm and extend our earlier observations [26] and are in general agreement with those of other investigators. For example, Bello et al. [27] reported finding karyotypic heterogeneity in ovarian fluids where no two cells displayed the same karyotype, but they could be shown to be clonally derived. Many semples in our study were similarly so heterogeneous that modal numbers could not be definitively determined, although structural abnormalities could be identified.

It has been previously shown that abnormalities of chromosomes 1 and 6 are common in ovarian cancer. Other studies on predominantly malignant effusions have shown that chromosome 3 is also frequently involved in rearrange- 


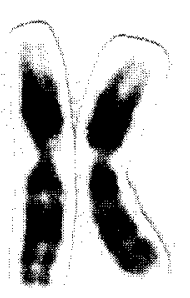

1

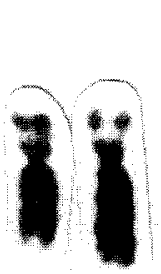

6

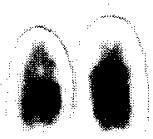

13

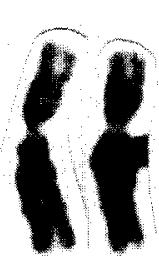

2
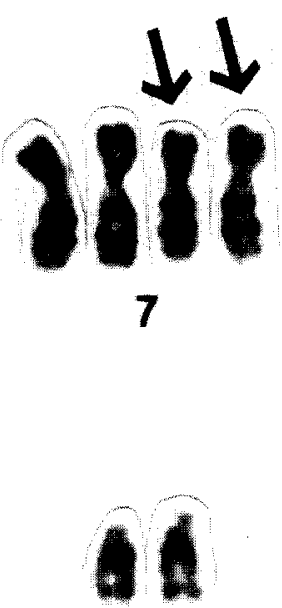

14
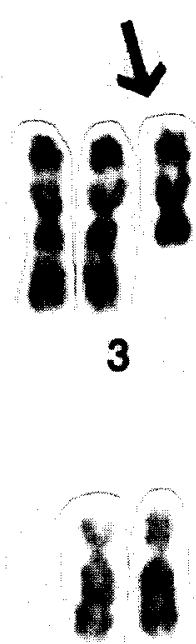

8

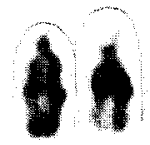

15

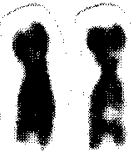

9

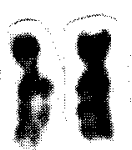

10

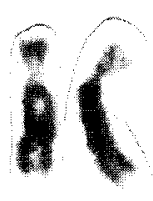

4

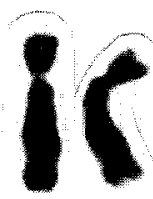

5

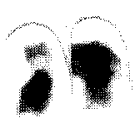

16

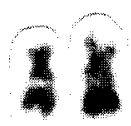

17

22

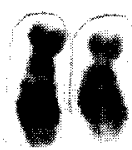

12

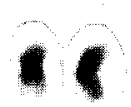

19

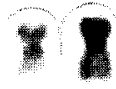

20

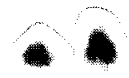

21
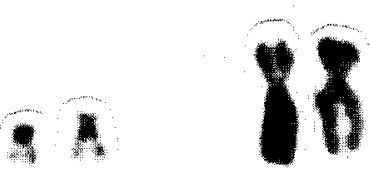

XY

Figure 3 Representative G-banded karyotype from case T89-321. Arrows indicate clonal abnormalities.

ments in these tumors $[27,28]$. In a recent study of primary ovarian tumors, the chromosomes most frequently altered were $1>11>3>7$ [29], whereas a similar study by Pejovic et al. [30] found that the chromosomes most frequently involved in structural rearrangements were 1,6 , and 11 . These authors also reported the findings of translocations of unknown material to $19 p$ in $7 / 11$ cases with bilateral ovarian carcinoma, and suggested that this might represent a specific marker characterizing a subset of patients. Although in our patient series we did not find 19p + markers, we did identify structural abnormalities involving 19q13. Similarly, Bello et al. [31] found $2 / 20$ cases with $19 q+$, rather than $19 p+$, markers, and Whang-Peng et al. [28] found $12 / 29$ cases with clonal structural abnormalities to have $19 q+$ markers of unknown origin. Differences in detection of $19 p+$ vs. $19 q+$ markers and the incidence of structural abnormalities regarding chromosome 19 may represent a function of differing in- terpretations or geographic heterogeneity of neoplasiaassociated chromosome aberrations [32].

In a study of stages III and IV ovarian carcinoma, Volm et al. [33] found that patients with aneuploid tumors had a reduced survival compared to patients who did not have aneuploid tumors. One phenomenon which might relate to tumor progression and acquisition of increasing chromosome number is amplification of cellular oncogenes. Sasano et al. [34] looked for amplification of the c-myc, int-2, and c-erbB2 oncogenes in benign and malignant ovarian tumors and showed that nearly half of the carcinomas that displayed amplification were aneuploid carcinomas, while none of the benign tumors showed gene amplification. In addition, they demonstrated a relationship between gene amplification and the serous histologic sub-type. In our patient sample of predominantly stage III and IV ovarian carcinomas, 12/54 (22\%) cases showed cytologic evidence of gene amplification in the 

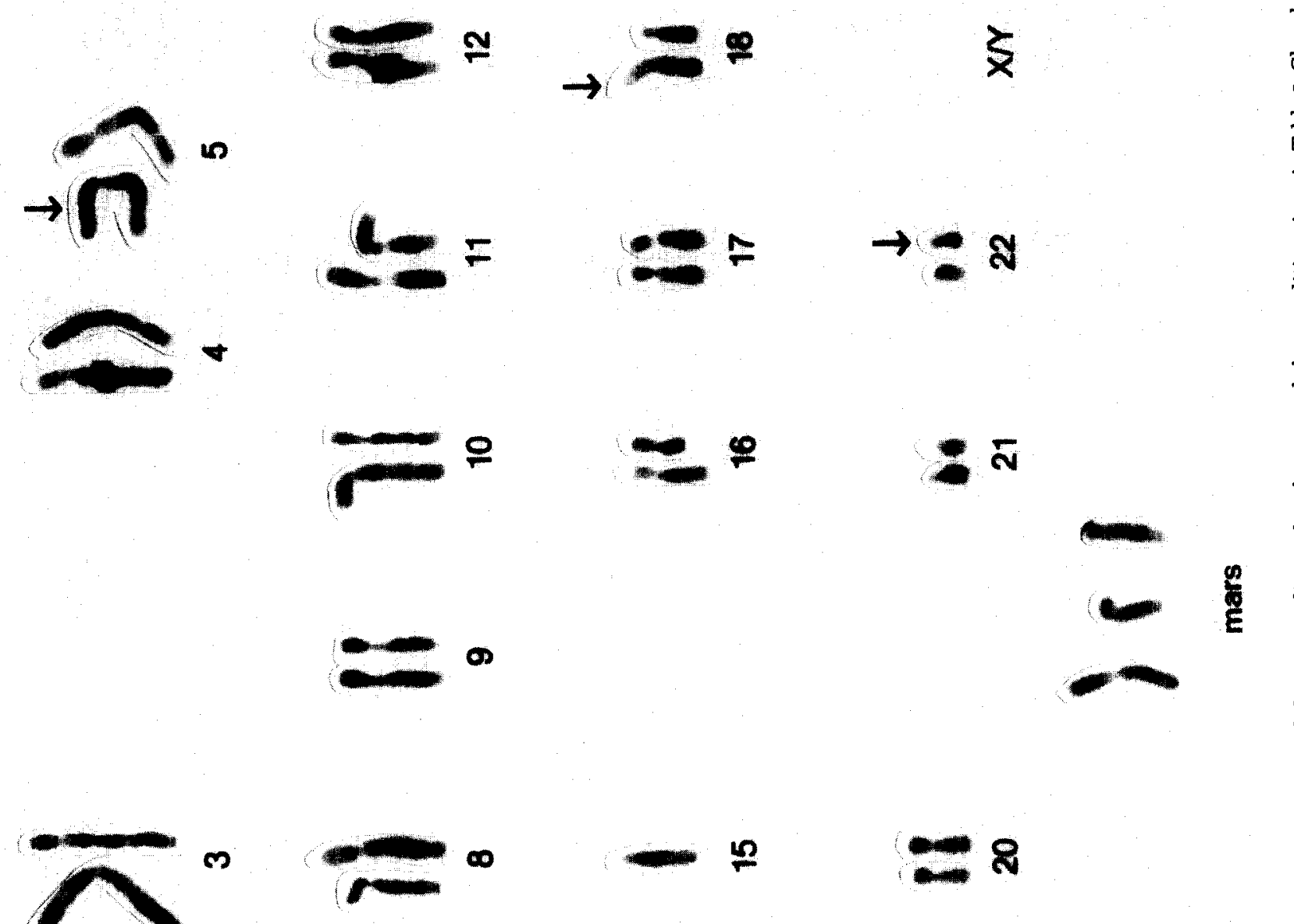

$\longrightarrow 2$

$-18$

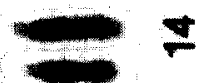

$-9$

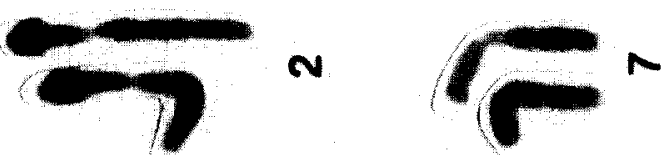

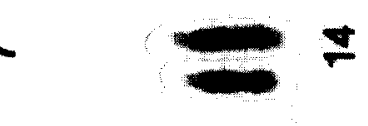
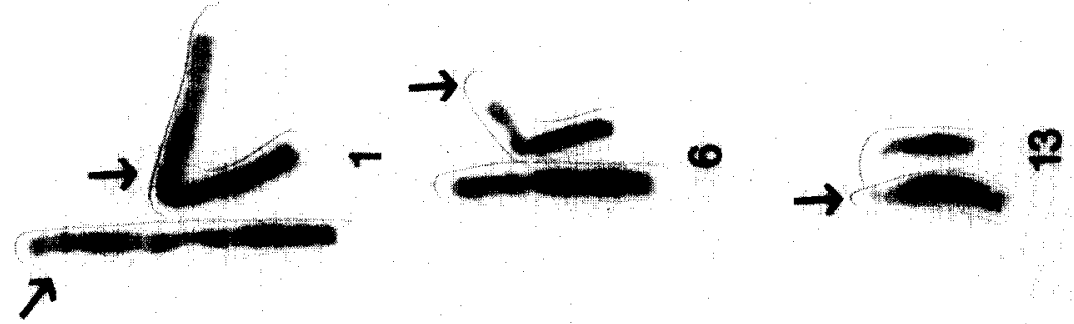


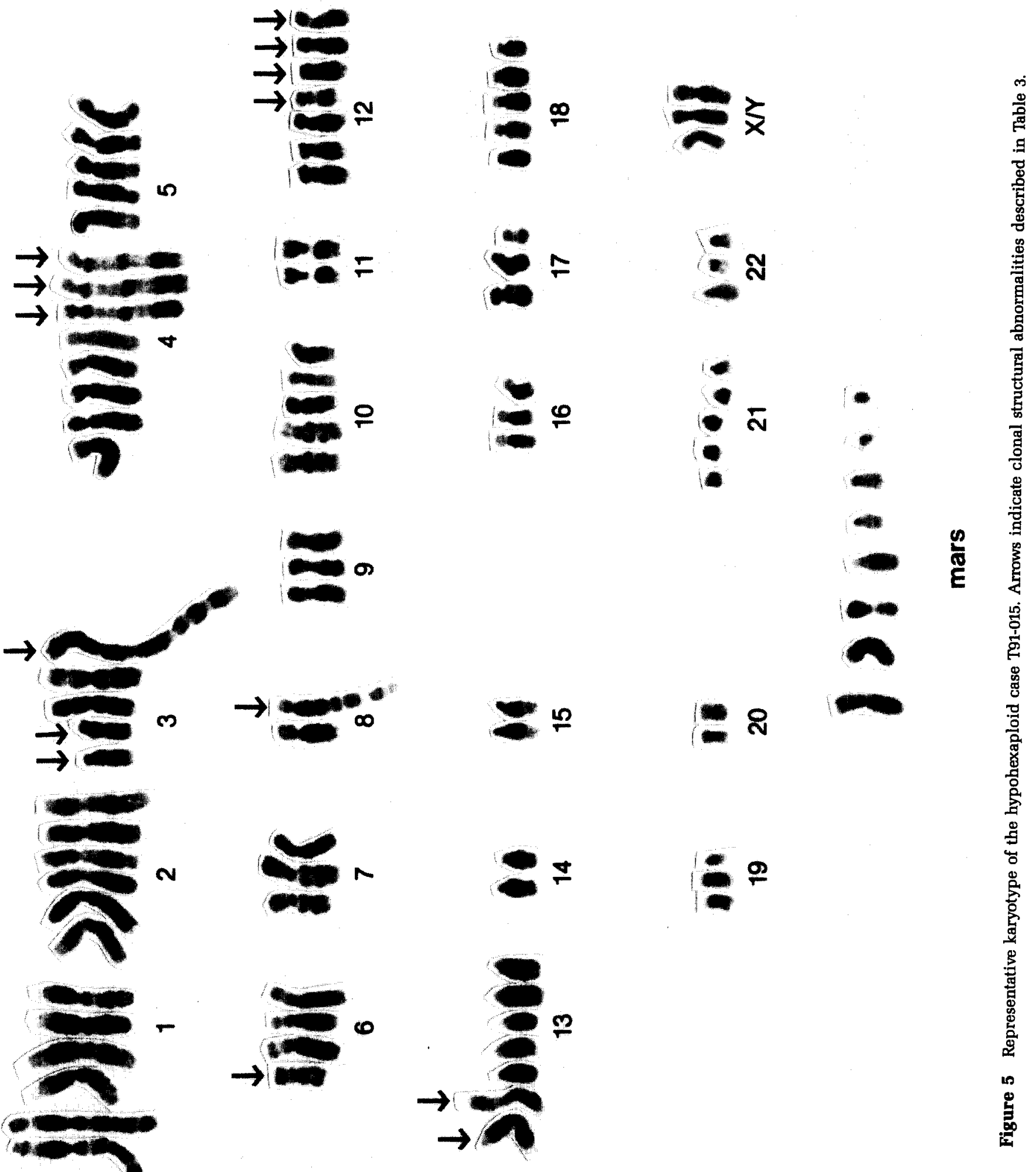




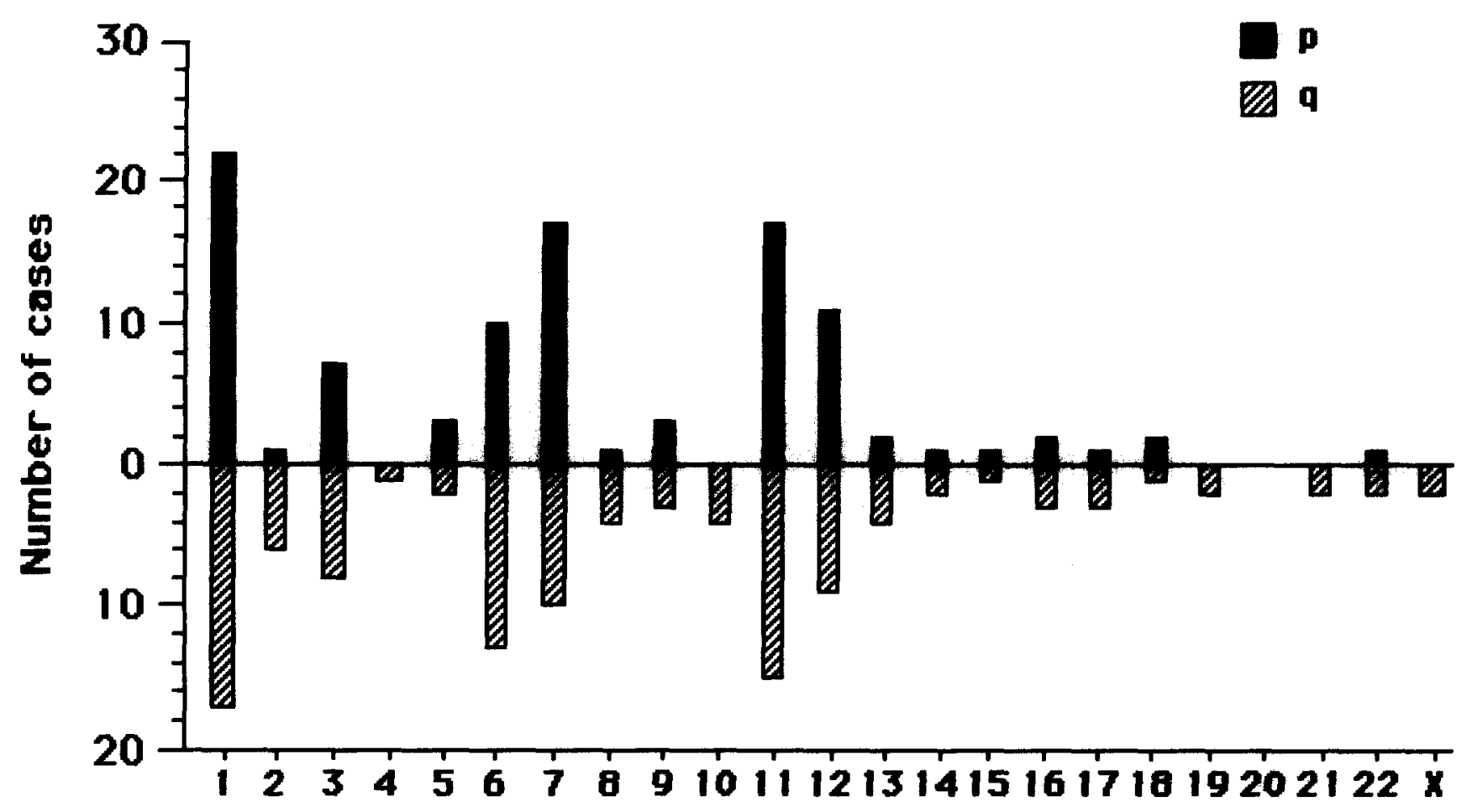

\section{Chromosome}

Figure 6 Histogram summarizing the distribution of clonal structural abnormalities in 52 cases of ovarian carcinoma.

form of homogeneously staining regions (HSRs). Ten of these (83\%) were serous tumors, one was endometrioid, and one was an undifferentiated stage I tumor.

While most tumors in this series displayed numerous and complex karyotypic alterations, some cases showed few abnormalities, and two of these had only numeric changes. Clonal gain of chromosomes 7 and 8 were the only abnormalities in T89-232, and loss of $X$ was found in the tumor from patient T90-064, who was shown to be a previously undiagnosed Turner's syndrome mosaic. Although the $-X$ was a constitutional abnormality in this patient, it is interesting that CSRP analysis showed that loss of the $\mathrm{X}$ chromosome was one of the most consistent findings in our series. Other cases were near-diploid and showed simple karyotypes with both numeric and structural abnormalities. In case T89-321, a well-differentiated stage I endometrioid carcinoma, the mainline karyotype was $49, \mathrm{XX},+\operatorname{del}(3)(q 21),+7,+7$. The stemline karyotype of T89-154, a well-differentiated stage III serous carcinoma, was $45, X,-X, i(1)(q 10),+7,-22$, while the mainline was 46 ,idem with random numeric gains. In a case of a poorly differentiated stage III carcinoma with an undifferentiated histologic sub-type, T88-286, the modal karyotype was hypodiploid [45] and displayed balanced, reciprocal translocations, unbalanced translocations, $i(1 \mathrm{q})$, and clonal loss of 15, 16,19, and both $X$ chromosomes. A representative karyotype from this case is given in Figure 4.

These cases are of interest because they contained a single or few chromosome abnormalities, which may represent "primary" changes important in those tumors' initiation, pro- motion, and/or early development. Nine of 13 cases in which clonal numeric abnormalities were identified (six neardiploid and three near-triploid) showed loss of at least one $\mathrm{X}$ chromosome relative to ploidy level. Loss of X chromosomes has also been previously reported by others. For instance, Pejovic et al. [30] found loss of the X in 3/4 abnormal near-diploid cases of bilateral ovarian carcinoma and, relative to ploidy level, in $7 / 7$ near-triploid and near-tetraploid tumors. Tanaka et al. [35] found loss of $X$ in 8/9 ovarian cancer cases, and Pejovic et al. [36] found loss of $X$ in 8/9 karyotypically abnormal carcinomas, relative to ploidy level. Furthermore, Pejovic et al. [37] found that loss of X was the only anomaly in the karyotype of an ovarian adenofibroma (although they also found +12 alone or in combination with additional numeric changes in six other benign ovarian tumors). It is tempting to speculate that loss of $\mathrm{X}$ may be a primary and/or predisposing event in ovarian cancer initiation.

While clonal losses were more common than gains (relative to ploidy levels in both diploid and triploid tumors), the most common gain of at least one normal homolog involved chromosome 7 ( $3 / 13$ cases, all diploid). In the study by Pejovic et al. [38], cytogenetic studies of four welldifferentiated malignant epithelial tumors (including a seropapillary ovarian adenocarcinoms and a squamous cell carcinoma which developed on an ovarian dermoid cyst) showed only simple numeric karyotype aberrations. Gain of chromosome 7 was common to all four cases. Gain of chromosome 7 followed by structural abnormalities of that chro- 

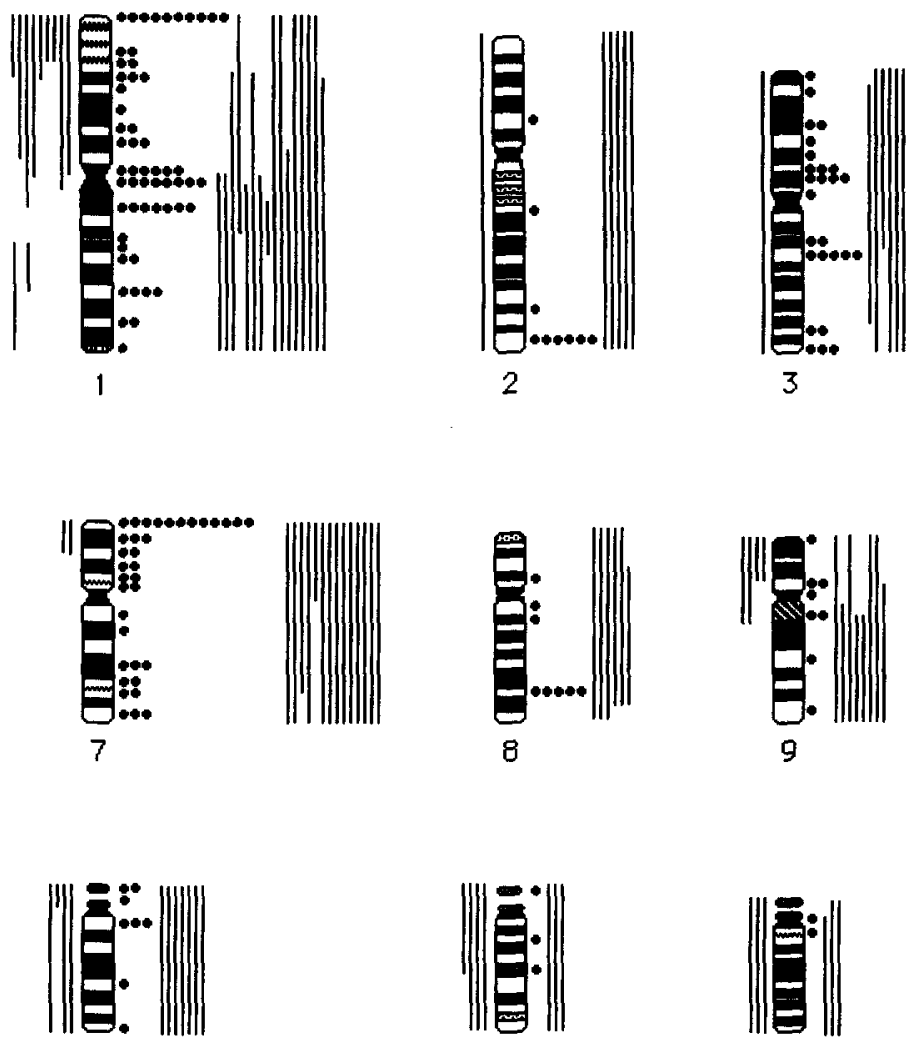

13

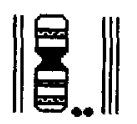

19
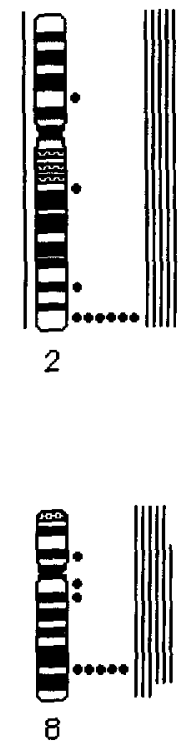

2

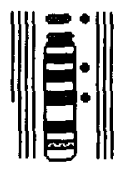

14

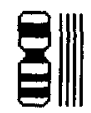

20

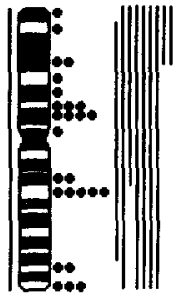

3

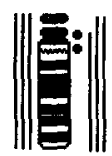

15

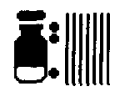

21

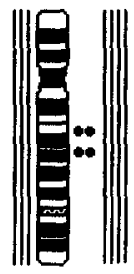

4

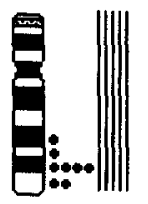

10
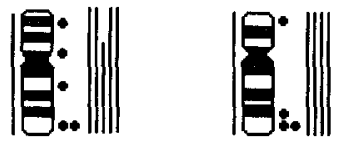

17

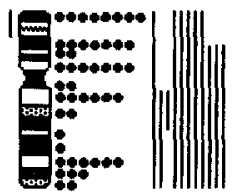

11

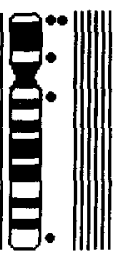

5

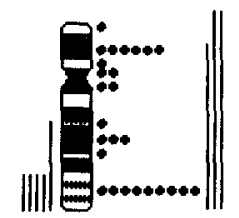

12

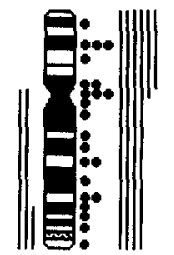

6

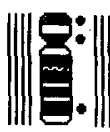

18

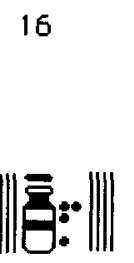

22

Figure 7 Summary of all identified breakpoints involved in clonal structural abnormalities (dots) from 52 cases of ovarian carcinoma. Chromosome segment representation profiles (CSRPs) from 13 cases that had complete and well-defined modal karyotypes are also shown. Lines on the right side of each chromosome's ideogram represent net gain of chromosomes or segments, and lines on the left represent net loss.

mosome may be an early, if not primary, change in at least a subset of patients. Trisomy 7 as a sole karyotype abnormality has been reported in a number of epithelial, mesenchymal, and neurogenic neoplasms, as well as in nonneoplastic tissues [39]. Although +7 alone may not strictly be a marker of malignant cells, it is not known whether +7 is a neutral karyotype imbalance or if it confers growth advantages on affected cells. Nonetheless, the significant number of chromosome 7 break points identified in our patient series and over-representation rivaled only by chromosome 1 suggests that chromosome 7 imbalances are associated with, if not a contributing or predisposing factor to, early tumor progression.

The only other normal homologs gained in near-diploid tumors in this series were chromosomes 8 and 12 (one case each). We have previously reported on an ascites fluid from ovarian cancer in which the only karyotypic abnormalities were inv(3), $+8,+12,+20$ [40]. Additionally, we have observed other cases of ovarian carcinoma with very simple karyotypes which have numeric abnormalities, including +8 and +12 , as sole abnormalities (unpublished data). It is possible that gain of chromosome 12 followed by structural rearrangement accompanying tumor progression is an important characteristic of a subset of patients with ovarian carcinoma. Evidence for this includes the finding by Pejovic et al. $[37,41]$ of +12 in some benign ovarian tumors and ovarian carcinomas, and the finding of frequent structural abnormalities of chromosome 12 in the present series.

Structural alterations involving chromosome 1 were found in $62 \%$ of the samples in this case series, an observation reported frequently in all human solid tumors. However, two of our cases with very simple karyotypes, T89-154 and T88286, displayed alterations of chromosome 1 [i(1q)], suggesting that rearrangements involving chromosome 1 may be an early event in tumor progression. In our patient series, we also noted a subset of patients with translocations of unknown material to chromosome band 1p36. These markers are similar in appearance to a $1 p+$ marker in a published karyotype of 


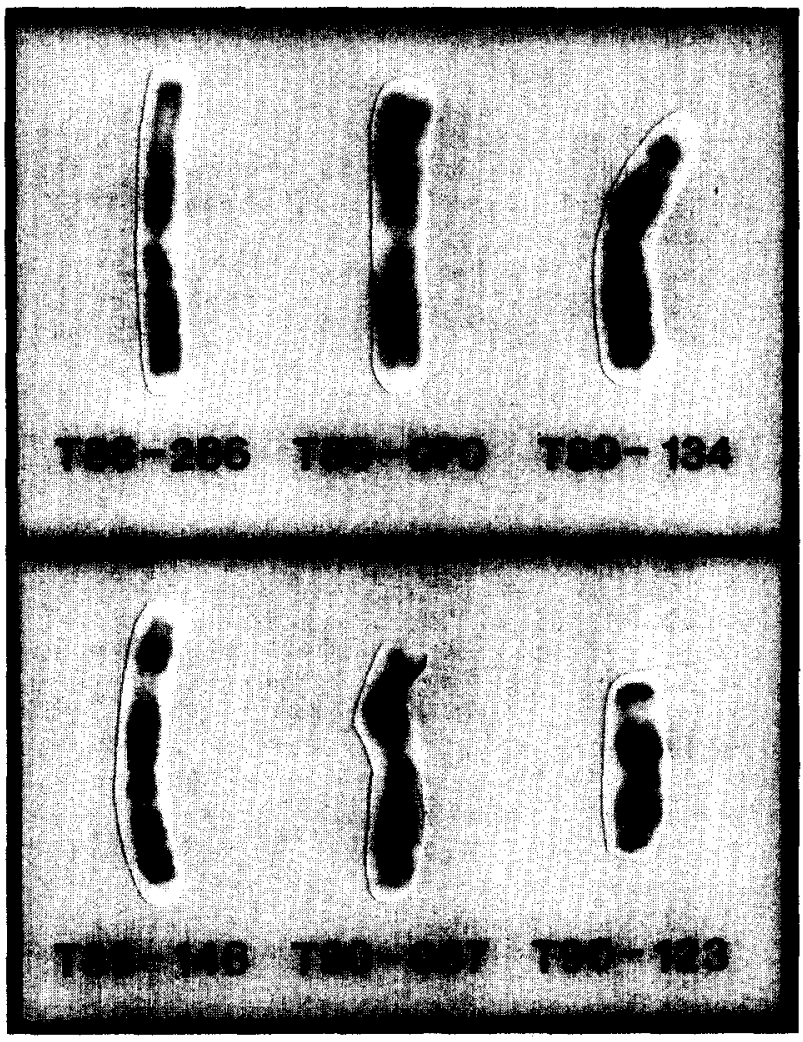

Figure 8 Examples of 1p + markers with similar morphology and banding patterns from six different cases of ovarien carcinoma. The marker from T89-148 was identified as a $\operatorname{der}(1) t(1 ; 11)(p 36 ; q 13)$, whereas the others have smaller pieces of chromosomal material from unknown origins.

Pejovic et al. [42], and another by Roberts and Tatersall [43]. Additionally, 1p + markers were reported in 2/9 cases by Tanaka et al. [35] and 10/29 cases by Whang-Peng et al. [28]. In most cases, translocated chromosomal segments are too small to identify their origins by standard banding methods. Future studies are planned combining chromosome microdissection [44] and fluorescent in situ hybridization methods in the hopes of revealing whether these represent consistent, specific translocations or only a common breakpoint involving translocations with varying donor chromosomes.

Karyotype abnormalities of chromosome 3 may also be important to early tumor progression in some patients because + del(3) (resulting in gain of the $3 p$ and proximal $3 q$ ) was the only structural abnormality in our case T89-321 (a patient with stage I disease). Bello et al. [31] reported a case of a pleural fluid from a patient with an ovarian primary whose karyotype only displayed +3 , and we have previously reported on the study of serial ascites fluid specimen samples where the stemline karyotype was 50,XX,inv(3), + inv(3), $+B,+12,+20$ [40]. A number of our cases with more complex karyotypes also had rearrangements of chromosome 3 , a finding that is in agreement with other studies.

Our findings suggest that certain karyotypic alterations in ovarian cancer may be related to histology. Specifically, alterations of chromosome 6 in our patient series correlated with an undifferentiated histologic sub-type, rather than the much more common serous sub-type, and were quite frequently found in cases with the most complex karyotypes.

In summary, our findings are consistent with the idea that nonrandom chromosome abnormalities can be identified in ovarian carcinoma and frequently involve chromosomes 1 , $3,6,7,11$, and 12 . Some of these karyotypic abnormalities (involving chromosomes 1,3 , and 7 , or loss of the $\mathrm{X}$ ) may be important to tumor initiation, whereas others (possibly involving 6, 11, and 12) may be related to tumor progression, histology, or metastasis. While further cytogenetic studies are warranted, examination of possible clinicopathologic correlations are underway and may shed light on the biologic significance of these chromosome rearrangements.

We would like to acknowledge members of the Gynecologic Cancer Committee of the Southwest Oncology Group for forwarding fresh human ovarian cancers to the Arizona Cancer Center for cytogenetic analysis. The major tumor contributors include Drs. Earl Surwit, Al Bonebrake, Darryl Wallace, Ken Hatch, and Francisco Ampuero. We would also like to thank Lee Wisner for technical assistance in the preparation of the figures. This work is supported by NCI grant CA-41183.

\section{REFERENCES}

1. Boring CC, Squires TS, Tong T (1991): Cancer Statistics, 1991, American Cancer Society.

2. Parkin DM (1989): Cancers of the breast, endometrium ovary: geographic correlations. Eur J Clin Oncol 25:1917-1925.

3. Bertelsen K (1990): Tumor reduction surgery and long-term survival in advanced ovarian cancer: a DACOVA study. Gynecol Oncol 38:203-209.

4. Omura GA, Brady MF, Homesley HD, Edgardo Y, Major FJ, Buchsbaum HJ, Parb RC (1991): Long-term follow-up and prognostic factor analysis in advanced ovarian carcinoma: the Gynecologic Oncology Group experience. J Clin Oncol 9:1138-1150.

5. Piver MS, Lele SB, Marchetti DL, Baker TR, Yoshiaki T, Emrich LJ (1988): The impact of aggressive debulking surgery and cisplatin-based chemotherapy on progression-free survival in stage III and IV ovarien carcinoma. J Clin Oncol 6:983-989.

6. Alberts DS, Dahlberg S, Green SJ, Garcia D, Hannigan EV, OTbole R, Stock-Novack D, Surwit EA, Malviya VK, Jolles C] (1993): Analysis of patient age as an independent prognostic factor for survival in a phase II study of cisplatin-cyclophosphamide versus carboplatin-cyclophosphamide in stages III (suboptimal) and IV ovarian cancer: a Southwest Oncology Group study. Cancer Suppl 71(2):618-627.

7. Friedlander ML, Dembo AJ (1991): Prognostic factors in ovarian cancer. Semin Oncol 18:205-212.

8. Alberts DS, Green S, Hannigan EV, OTbole R, Stock-Novack D, Anderson P, Surwit EA, Malviya VK, Nahhas WA, Jolles CJ (1992): Improved therapeutic index of carboplatin plus cyclophosphamide: final report by the Sonthweat Oncology Group of a phase III randomized trial in stages III and IV ovarian cancer. J Clin Oncol 10:706-717.

9. Alberts DS, Liu PY, Hannigan E, Surwit EA, O'Sullivan J, Garcia D, Richardson M, Williams S, Young J, O'Tbole R (1990): Relationship between serum CA-125 levels at chemotherapy courses 3 and 6 and the outcome of second-look surgery status in advanced ovarian cancer. Proc Amer Assoc Cancer Res 31:189 (abstract \#1121).

10. Mogensen O, Mogenson B, Jakobsen A (1990): Predictive value 
of CA-125 during early chemotherapy of advanced ovarian cancer. Gynecol Oncol 37:44-46.

11. Hunter VJ, Lee D, Helms M, Soper JT, Berchuck A, Clark-Pearson DL, Bast Jr. RC (1990): The prognostic significance of CA-125 half-life in patients with ovarian cancer who have received primary chemotherapy after surgical cytoreduction. Am J Obstet Gynecol 163:1164-1167.

12. Hawkins RE, Roberts K, Wiltshaw E, Mundy J, Fryatt IJ, McReady VR (1989): The prognostic significance of the half-life of serum CA-125 in patients responding to chemotherapy for epithelial ovarian carcinoma. Br J Obstet Gyneacol 96:1395-1399.

13. Sevelda P, Schemper M, Spona J (1989): CA-125 as an independent prognostic factor for survival in patients with epithelial ovarian cancer. Am J Obstet Gynecol 161:1213-1216.

14. Heim S, and Mitelman F (1987): Cancer Cytogenetics, Alan Liss, New York.

15. Mitelman F, Kaneko Y, Trent J (1991): Report of the committee on chromosome changes in neoplasia. Human Gene Mapping 11 (1991). Cytogenet Cell Genet 58:1-2200.

16. Lee JH, Kavanagh J, Wildrick DM, Wharton JT, Blick M (1990): Frequent loss of heterozygosity on chromosomes $6 q, 11$, and 17 in human ovarian carcinomas. Cancer Res 50:2724-2728.

17. Serov SF, Scully RE, Sobin LH (1973): Histological typing of ovarian tumours. In: International; Histological Classification of Tumours. Geneva, World Health Organization.

18. Russell P, Bannatyne P (1989): Surgical Pathology of the Ovaries, Churchill Livingston, London.

19. FIGO: International Federation of Gynecology and Obstetrics (1971): Classification and staging of malignant tumors in the female pelvis. Acta Obstet Gynaecol Scand 50:1-7.

20. Trent JM, Thompson FH (1987): In: Molecular genetics of mammalian cells. Vol. 151 of Methods in Enzymology, Gottesman M, ed. Academic Press, San Diego, pp. 267-279.

21. Leibovitz A (1985): In: Maramorosh K, ed. Advances in cell culture. Vol. 4, Academic Press, New York, pp. 249-260.

22. ISCN (1985): An International System for Human Cytogenetic Nomenclature, Harnden DG, Klinger HP, eds, published in collaborations with Cytogenet Cell Genet (Karger, Basel 1985); also in Birth Defects: Original Article Series, Vol. 121, No. 1 (March of Dimes Birth Defects Foundation, New York, 1985).

23. ISCN (1991): Guidelines for Cancer Cytogenetics, Supplement to An International System for Human Cytogenetic Nomenclature, F. Mitelman, ed. S. Karger, Basel (1991).

24. Brodeur GM, Tsiatis AA, Williams DL, Luthardt FW. Green AA (1982): Statistical analysis of cytogenetic abnormalities in human cancer cells. Cancer Genet Cytogenet 7:137-152.

25. Thompson F, Emerson J, Dalton WS, Yang J-M, McGee D, Villar H, Knox S, Massey K, Weinstein R, Bhattacharye A, Trent J (1994): Clonal chromosomal abnormalities in human breast carcinomas: I: 28 cases with primary disease. Genes Chrom Cancer (in press).

26. Trent JM (1985): Prevalence and clinical significance of cytogenetic abnormalities in human ovarian cancer. In: Ovarian Cancer, DS Albets, EA Surwit, eds. Martinus, Nijhof Publishers, New York, pp. 1-21.

27. Bello MJ, Moreno S, Rey JA (1990): Involvement of 9p in metastatic ovarian adenocarcinomas. Cancer Genet Cytogenet 45: 223-229.
28. Whang-Peng J, Knutsen T, Douglass EC, Chu E, Ozols RF, Hogan WM, Young RC (1984): Cytogenetic studies in ovarian cancer. Cancer Gonet Cytogenet 11:91-106.

29. Gallion HH, Powell DE, Smith LW, Morrow JK, Martin AW, van Nagell JR, Donaldson ES (1990): Chromosome abnormalities in human epithelial ovarian malignancies. Gynecol Oncol 38: 473-477.

30. Pejovic T, Heim S, Mandahl N, Elmfors B, Furgyik S, Floderus U-M, Helm G, Willen H, Mitelman F (1991): Bilateral ovarian carcinoma: cytogenetic evidence of unicentric origin. Int J Cancer 47:358-361.

31. Bello MJ, Rey JA (1990): Chromosome aberrations in metastatic ovarian cancer: relationship with abnormalities in primary tumors. Int J Cancer 45:50-54.

32. Johansson B, Mertens F, Mitelman F (1991): Geographic heterogeneity of neoplasia-associated aberrations. Genes Chrom Cancer 3:1-7.

33. Volm M, Bruggemann A, Marianne Gunther, Kleine W, Pfleiderer A, Vogt-Schaden M (1985): Prognostic relevance of ploidy, proliferation, and resistance-predictive tests in ovarian carcinoma. Cancer Res 45:5180-5185.

34. Sasano H, Garrett CT, Wilkinson DS, Silverberg S, Comerford J, Hyde J (1990): Protooncogene amplification in human ovarian neoplasms. Hum Pathol 21:382-391.

35. Tanaka K, Boice CR, Testa JR (1989): Chromosome aberrations in nine patients with ovarian cancer. Cancer Genet Cytogenet 43:1-14.

36. Pejovic T, Heim S, Mandahl N, Elmfors B, Flodderus U-M, Furgyik S, Helm G, Willen H, Mitelman F (1989): Consistent occurrence of a 19p + marker chromosome and loss of 11p material in ovarian seropapillary cystadenocarcinomas. Genes Chrom Cancer 1:167-171.

37. Pejovic T, Heim S, Mandahl N, Elmfors B, Floderus U-M, Furgyik S, Helm G, Willen H, Mitelman F (1990): Trisomy 12 is a consistent chromosomal aberration in benign ovarian tumors. Genes Chrom Cancer 2:48-52.

38. Pejovic T, Heim S, Orndahl C, Jin Y, Mandahl N, Willen H, Mitelman F (1990): Simple numerical chromosome aberrations in well-differentiated malignant epithelial tumors. Cancer Genet Cytogenet 49:95-101.

39. Johansson B, Heim S, Mandahl N, Mertens F, Mitelman F (1993): Trisomy 7 in nonneoplastic cells. Genes Chrom Cancer 6: 199-205.

40. Trent JM, Thompson FH, Buick RN (1985): Generation of clonal variants in a human ovarian carcinoma studied by chromosome banding analysis. Cancer Genet Cytogenet 14:153-161.

41. Pejovic T, Heim S, Mandahl N, Baldetorp B, Elmfors B, Floderus U-M, Furgyik S, Helm G, Himmelmann A, Willen H, Mitelman $F$ (1992): Chromosome aberrations in 35 primary ovarian carcinomas. Genes Chrom Cancer 4:58-68.

42. Pejovic T, Heim S, Mandahl N, Floderus U-M, Willen H, Mitelman F (1990): Complex karyotypic anomalies, including an i(5p) marker chromosome, in malignant mixed mesodermal tumor of the ovary. Cancer Genet Cytogenet 46:65-69.

43. Roberts CG, Tatersall MHN (1990): Cytogenetic study of solid ovarian tumors. Cancer Genet Cytogenet 48:243-253.

44. Meltzer P, Guan X-Y, Trent JM (1994): Telomere capture stabilizes chromosome breakage. Nature Genet (in press). 